\title{
Review Study on the Effect Surface Spinal Stimulation on Autonomic Nervous System in Spinal Cord Injury Patient
}

\author{
Kaur $^{1}$, Bhavkiran, Narkeesh ${ }^{2,}$ A.
}

${ }^{1}$ Research Student, Department of Physiotherapy, Punjabi University, Patiala-147001, Punjab, India

${ }^{2}$ Prof. Department of Physiotherapy, Punjabi University, Patiala-147001, Punjab, India. Email: narkeesh@yahoo.com

\section{Abstract}

Background: Spinal cord injury is a disabling condition can lead to various autonomic disturbances of thermoregulatory dysfunction, autonomic hyperreflexia, vasomotor dysfunction, and bowel and bladder dysfunction. Different treatment techniques have been used for its management. In the present study, surface spinal stimulation has been used to find the effect on bladder, on skin resistance and skin temperature through comparing pre and post- treatment on a male with spinal cord injury.

Method: A 29-year-old-male suffered complete spinal cord injury at level D12 during a car accident. The case was diagnosed and treated for compression fracture of D11-D12 with paraplegia with bowel and bladder dysfunction. The subject was administered surface spinal stimulation with a carrier frequency of $2500 \mathrm{~Hz}$, beat frequency $20 \mathrm{~Hz}$ applied continuously for 45 min with two adhesive rectangular electrodes of size $(4.5 \times 9 \mathrm{~cm})$ placed on each side of supine $5 \mathrm{~cm}$ apart over T10- L2 level paravertebrally. Results and Conclusion: The present study found that surface spinal stimulation with medium frequency current of beat frequency $20 \mathrm{~Hz} w a s$ effective in improving detrusor pressure, bladder sensations, infused fluid volume and bladder capacity of the patient with spinal cord injury. Electrical stimulation over the paravertebral region also demonstrated improvement in the skin resistance, but had no significant effect over skin temperature.

KEY WORDS: Surface spinal cord stimulation, Autonomic nervous system, Thermoregulation, Skin resistance, Bowel and bladder control.

\section{Introduction}

Spinal cord injury (SCI) is a global epidemic, and was considered as "untreatable ailment" decades ago. This disabling condition causes paralysis of voluntary musculature which leads to reduced mobility as well as impairment of vocational and self care activities. (Sunder, 2010). According to the Indian statistics, about 20 percent of all spinal injuries lead to neurological deficit in the form of paraplegia following thoracolumbar spine injuries, or quadriplegia following cervical spine injuries
(Maheshwari, 2006). The causes of injury could be direct or indirect spinal trauma which causes damage to the cord and the symptom may vary according the level of injury. Cord involvement following neurological lesion could be complete or incomplete. After spinal cord injury, patient presents with primary and secondary complications depending upon the level and type of injury. These complications could be musculo-skeleton and autonomic disturbances. 
The common autonomic disturbances following spinal cord injury are thermoregulatory dysfunction, autonomic hyperreflexia, vasomotor dysfunction, bowel and bladder dysfunction. The Autonomic Nervous System (ANS) plays a key role in the regulation of many physiologic processes, mediated by supraspinal control from centers in the central nervous system. Disruption of spinal cord decreases the ability to sympathetically control blood pressure and to regulate body temperature, most likely due to the impairment of autonomic and somatic nervous systems (Hutchinson, 1875). This condition is described as partial poikilothermia; ability to increase heat production by shivering is decreased. The ability of the body to sweat and to vasodilate the skin is impaired in the area below the spinal lesion (Attia et al., 1983). The vasomotor changes following SCI include disturbance or complete loss of internal thermal regulatory responses, causes of this is bladder or rectal distension, pressure sores, urinary stones, bladder infection, urethral or bladder irritation and environmental temperature changes.

Bladder dysfunction has been reported as a serious medical complication following spinal cord injury. There are two main type of bladder dysfunction observed after spinal cord injury, either the patient is unable to store the urine or experiences failure to empty it. The failure to store the urine is detrusor hyperreflexia, often seen in patients above L1, and is characterized by both detrusor and sphincter overactivity, with both contracting reflexively when stretched. This built higher pressures in bladder leads to incontinence, incomplete emptying and reflux. Second type of bladder dysfunction is detrusor-sphincter dyssynergia-impaired coordination between bladder contraction and sphincter relaxation - is also a common finding in patients with SCIs.

Primary goal of bladder management is to empty the bladder under low pressure to prevent renal failure and maintain continence, treatment should be acceptable to the individual. Management of bladder includes periodic complete emptying of bladder with clean intermittent catheterization which is one of the effective ways to manage the patient with detrusor hyperreflexia and incontinence. Common approaches for bladder management include behavioral therapy, catheters, pharmacotherapy and electro-stimulation. Electrical stimulation over the sacral afferent nerves has reported to reduce incontinence and hyperactivity of bladder (Young et al., 2002). Sacral anterior root stimulation, S3 neuro-modulation, pudenendal nerve stimulation, anal or vaginal and more general surface spinal stimulation have been evaluated for various conditions, such as stress incontinence, irritative syndrome and to reduce external urethral sphincter spasm (Amarenco, 2003). 
Spinal cord stimulation through epidural and surface electrodes was first used for the management of intractable pain, later it has also been for the rehabilitation of multiple sclerosis and other chronic neurological disorders. The workers working with the patients with multiple sclerosis generally observe that the main benefits of spinal cord stimulation are in bladder function (Abbate et al., 1977). Following spinal stimulation clinical and urodynamic improvement in the bladder dysfunction has been reported in spinal cord injury (Richardson and McLone, 1978), cerebral palsy (Campos et al., 1978) and in multiple sclerosis. Apart from the effect on bladder, little attention has been given to the other effects that spinal stimulation may have upon the autonomic nervous system. It was reported that patients with peripheral vascular diseases experience sensation of warmth and alternations in blood flow in the skin after spinal stimulation (Tallis et al., 1983). Researcher considers that surface spinal stimulation can influence the function of bladder, skin resistance and skin temperature. The present study was to aimed at finding the effect of surface spinal stimulation on bladder, on skin resistance and skin temperature through comparing pre and post values of urodynamics testing, galvanic skin response and Infra-red thermometer.

Case Report:
A 29 years old male, met with a car accident on April, 2011. His present chief complaints were inability to walk independently, irritation and difficulty in passing the urine. After the accident the patient was taken to the nearest hospital at Shimla. After emergency acute care, patient was referred to NIMS hospital, Mohali. The CT scan and MRI revealed spinal cord injury and D12 compressed fracture. The patient was diagnosed with T12 compressed injury with lower limb paraplegia and bladder and bowel involvement. The patient underwent fixation at D11-L1 level and kept in the hospital for 15 days. He received physiotherapy treatment session from NIMS and Ivy hospital, Mohali. The subject was catheterized for initial 3 months and after that patient was advised to use clean intermittent catheterization after self-voiding. Patient has been taking pruflox $(600 \mathrm{mg})$ to avoid urinary tract infections and medicine for constipation. At rehabilitation centre of Ivy hospital, patient received passive range of motion exercises and stretching for hamstrings, quadriceps and calves. He did standing and walking in parallel bars with hipknee-foot orthosis (HKFO), balance training on swiss ball and posture training in front of mirror. Patient also did exercises to improve his functional status.

On examination, the vitals of the patient were normal. No abnormality of skin was observed, mid-pitting odema over both ankles was observed. Patient had old scars and marks of stitches were 
seen over nose and forehead. Patient had developed tightness of left dorsiflexors and foot drop deformity on right side. Patient was able to walk with HKFO and walker under supervision, but was able to use wheelchair independently. The patient was cooperative, alert and well oriented to time, place and person. The higher mental function and cranial nerves were normal. The superficial sensation of light touch, temperature, pin prick and deep sensations were intact upto L4 level. Superficial anal and bulbocavernous reflex were absent. The deep reflexes i.e. biceps, triceps, supinator reflexes were intact and knee jerk, ankle jerk and plantar reflex were absent. The patient had flexor spasm and was caused by any noxious stimulation to the feet.

\section{Materials \& Methods}

The patient was intructed to lie in the supine position and eight skin temperature measuring sites were marked over the lower limb. Skin temperature was recorded with the help of hand held thermometer (IRL 300, Kusam-Medico), at the distance of $10-15 \mathrm{~cm}$. Cystometric values of prior to surface spinal stimulation, cystometric values of infused fluid volume (IV), detrusor pressure (Pv), first sensation (FS), first desire (FD), normal desire (ND) and bladder capacity (BC) were measured. The actual and basal galvanic skin responses were recorded using galvanic skin meter (GBF-2000, Medic Aid) via applying probes over the $2^{\text {nd }}$ and $4^{\text {th }}$ toe of right foot for 10 to 15 minutes. The surface spinal stimulation with a carrier frequency of $2500 \mathrm{~Hz}$, beat frequency $20 \mathrm{~Hz}$ was applied continuously for $45 \mathrm{~min}$ with two adhesive rectangular electrodes of size $(4.5 \times 9 \mathrm{~cm})$ placed on each side of supine $5 \mathrm{~cm}$ apart over T10-L2 level paravertebrally (Wang et al., 2000). Then post-surface spinal stimulation values of cystometric values, GSR and infrared thermometer were recorded in the patient after electrical stimulation.

\section{Results:}

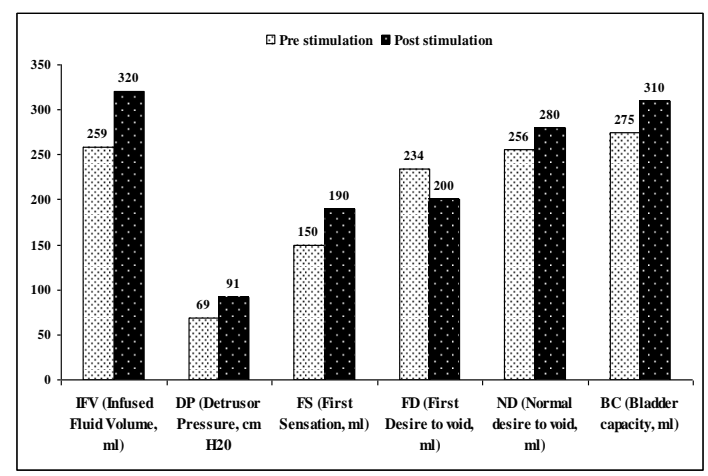

Figure 1: Comparison of Mean Value of Cystometric Variables at Pre- Intervals within the group

Table 1: Staistical comparison of skin temperature measured from thigh area.

Comparison

PRE Vs POST

$\begin{array}{lcl}\text { RTAn }\left({ }^{\circ} \mathrm{C}\right) & -2.138 & \mathrm{P}<0.05 \\ \text { LTAn }\left({ }^{\circ} \mathrm{C}\right) & -2.500 & \mathrm{P}<0.05 \\ \text { RTPs }\left({ }^{\circ} \mathrm{C}\right) & -2.138 & \mathrm{P}<0.05 \\ \text { LTPs }\left({ }^{\circ} \mathrm{C}\right) & -2.138 & \mathrm{P}<0.05 \\ \text { RTLa }\left({ }^{\circ} \mathrm{C}\right) & -2.500 & \mathrm{P}<0.05 \\ \text { LTLa }\left({ }^{\circ} \mathrm{C}\right) & -2.138 & \mathrm{P}<0.05 \\ \text { RTM }\left({ }^{\circ} \mathrm{C}\right) & -2.138 & \mathrm{P}<0.05 \\ \text { LTM }\left({ }^{\circ} \mathrm{C}\right) & -2.138 & \mathrm{P}<0.05\end{array}$


The pre and post-stimulation values of three measures were compared. The infused fluid volume (IV) on cystometry of the patient before stimulation was 259 $\mathrm{ml}$ and after stimulation was $320 \mathrm{ml}$. The pre-stimulation detrusor pressure $(\mathrm{Pv})$ of patient was $69 \mathrm{~cm} \mathrm{H}_{2} \mathrm{O}$, while poststimulation value was $91 \mathrm{~cm} \mathrm{H} 2 \mathrm{O}$. The pre-stimulation first sensation (FS) was felt at $150 \mathrm{ml}$ and post-stimulation first sensation was at $190 \mathrm{ml}$. The prestimulation first desire (FD) to void was at $234 \mathrm{ml}$ and post-stimulation value was $200 \mathrm{ml}$. Pre-stimulation normal desire (ND) to void was $256 \mathrm{ml}$ and poststimulation value was $280 \mathrm{ml}$. Bladder capacity on pre-stimulation cystometry was $275 \mathrm{ml}$ and on post-stimulation cystometry was $310 \mathrm{ml}$. The after stimulation cystometric values of IV, Pv, FS and BC were improved as presented in figure 1.

Table 2 : Staistical comparison of skin temperature of calf and foot areas.

\begin{tabular}{lcc}
\hline Comparison & \multicolumn{2}{c}{ PRE Vs POST } \\
& t value & P value \\
\cline { 2 - 3 } RCA $\left({ }^{\circ} \mathrm{C}\right)$ & -4.000 & $\mathrm{P}<0.05$ \\
LCA $\left({ }^{\circ} \mathrm{C}\right)$ & -4.000 & $\mathrm{P}<0.05$ \\
$\operatorname{RCP}\left({ }^{\circ} \mathrm{C}\right)$ & -2.138 & $\mathrm{P}<0.05$ \\
LCP $\left({ }^{\circ} \mathrm{C}\right)$ & -2.138 & $\mathrm{P}<0.05$ \\
RFD $\left({ }^{\circ} \mathrm{C}\right)$ & -1.177 & $\mathrm{P}>0.05$ \\
LFD $\left({ }^{\circ} \mathrm{C}\right)$ & $-\mathbf{1 . 6 3 3}$ & $\mathrm{P}>0.05$ \\
RFP $\left({ }^{\circ} \mathrm{C}\right)$ & $-\mathbf{0 . 7 8 4}$ & $\mathrm{P}>0.05$ \\
LFP $\left({ }^{\circ} \mathrm{C}\right)$ & $-\mathbf{0 . 7 8 4}$ & $\mathrm{P}>0.05$ \\
\hline
\end{tabular}

The pre-stimulation values of actual galvanic skin resistance was76 $\mathrm{k} \Omega$ and post-stimulation values was $246 \mathrm{k} \Omega$. The pre and post-stimulation values basal galvanic skin resistance were $84 \mathrm{k} \Omega$ and $271 \mathrm{k} \Omega$ (figure 2). The pre-stimulation Date of Communication: Sep.1t, 2013 Date of Acceptance: Dec. 28, 2013 skin temperature over the thigh area of right leg were $31^{\circ} \mathrm{C}$ on anterior aspect, $33^{\circ} \mathrm{C}$ on posterior aspect, $32^{\circ} \mathrm{C}$ on lateral aspect and $30^{\circ} \mathrm{C}$ on medial aspect. The post-stimulation values of right thigh were $30^{\circ} \mathrm{C}$ on anterior aspect, $29^{\circ} \mathrm{C}$ on posterior aspect, $29^{\circ} \mathrm{C}$ on lateral aspect and $29^{\circ} \mathrm{C}$ on medial aspect (figure 3 ). The pre-stimulation skin temperature of left thigh were $31^{\circ} \mathrm{C}$ on anterior aspect, $31^{\circ} \mathrm{C}$ on posterior aspect, $30^{\circ} \mathrm{C}$ on lateral aspect and $30^{\circ} \mathrm{C}$ on medial aspect. The poststimulation values of left thigh were $30^{\circ} \mathrm{C}$ on anterior aspect, $30^{\circ} \mathrm{C}$ on posterior aspect, $30^{\circ} \mathrm{C}$ on lateral aspect and $32^{\circ} \mathrm{C}$ on medial aspect (Fig.4).

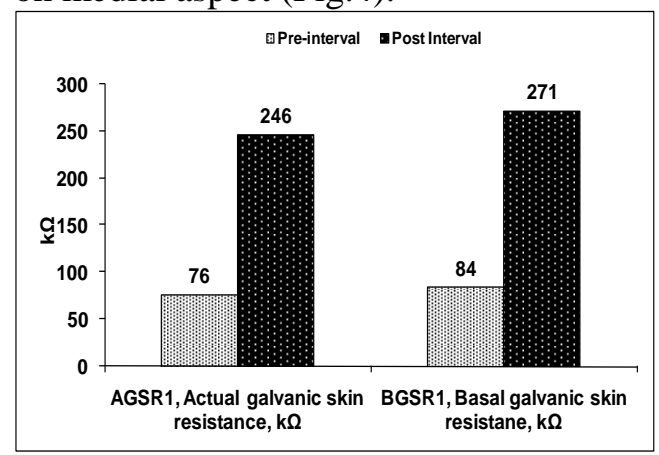

Figure 2: Comparison of Mean Values of AGSR (Actual Galvanic Skin Resistance) and BGSR (Basal Galvanic Skin Resistance) before and after stimulations.

The right foreleg pre-stimulation values $30^{\circ} \mathrm{C}$ on anterior aspect and $30^{\circ} \mathrm{C}$ over posterior aspect. The poststimulation values of right foreleg were $29^{\circ} \mathrm{C}$ over anterior and $31^{\circ} \mathrm{C}$ over posterior aspect. Pre-stimulation values of left foreleg over anterior aspect $29^{\circ} \mathrm{C}$, over posterior aspect $29^{\circ} \mathrm{C}$ and poststimulation values of left foreleg over anterior aspect $30^{\circ} \mathrm{C}$, over posterior aspect $30^{\circ} \mathrm{C}$ (Fig-5). The pre-stimulation value of right dorsal aspect $32^{\circ} \mathrm{C}$, right planter aspect $32^{\circ} \mathrm{C}$ and post-stimulation value of dorsal aspect was $33^{\circ} \mathrm{C}$ and planter aspect 
was $33^{\circ} \mathrm{C}$. The pre-stimulation values of left dorsal aspect was $27^{\circ} \mathrm{C}, 29^{\circ} \mathrm{C}$ over left planter aspect and post-stimulation value of left dorsal aspect was $29^{\circ} \mathrm{C}$ and $29^{\circ} \mathrm{C}$ over left planter aspect.

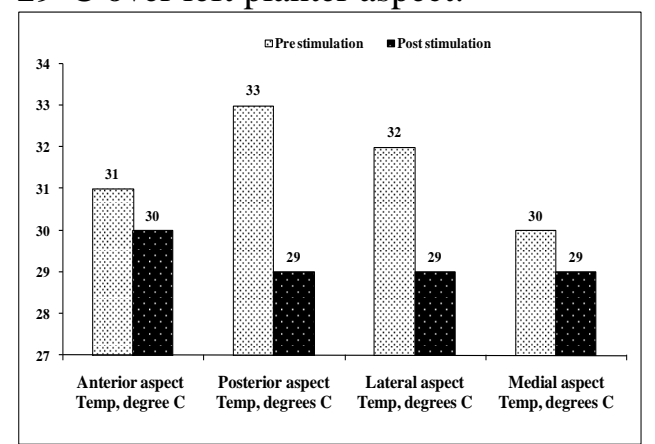

Figure 3: Comparison of Mean Values of Pre- and Post- stimulation Skin Temperature of Right Thigh

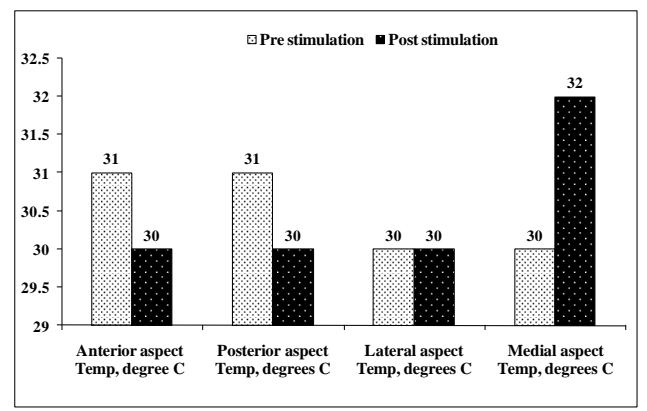

Figure 4: Comparison of Mean Values of Pre- and Post- stimulation Skin Temperature of Left thigh.

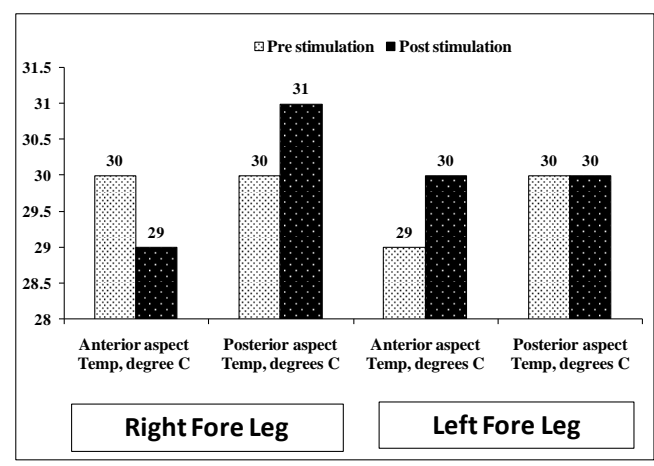

Fig 5: Comparison of Mean Values of Pre- and Poststimulation Skin Temperature of right $\&$ left forelegs.

\section{Discussion}

The results of this experimental study demonstrated that surface spinal stimulation improved the cystometric values and skin resistance in spinal cord injury subject. The cystometric values of urodynamics are subjective tool, to assess bladder function. In present study, inhibitory effect of stimulation was observed over the bladder sensations, which increased bladder capacity. The results of the study were in accordance with two studies reported significant reduction of bladder sensations following electrical stimulation of tibial and pudendal nerve stimulation due to inhibitory effect of sacral afferent pathways in hyperreflexic bladder and by depolarization of somatic sacral afferent fibers (Young et al, 2002; Amerenco et al, 2003). The possible explanation for the findings was that the low frequency stimulation of $5 \mathrm{~Hz}$, shown optimal inhibitory effect and high frequency current of $50 \mathrm{~Hz}$, reported to achieve urethral closure (Previnaire et al, 1998).

Parasympathetic electrical stimulation may activate large diameter afferent fibers of paravertebral region, which may modulate the interneuronic activities of several spinal segments. The same method of electrical stimulation proposed to improve control of stretch reflex and to modulate the transmission of afferent or efferent impulses resulting from generalized desensitization of spinal pathways (Wang et al., 2000). Brindley (1973) reported that the smooth muscles 
of detrusor relax more slowly than the striated muscles of urethral sphincter, develop pressure gradient and cause micturition. Sympathetic skin changes are under the control of autonomic nervous system. The results of the present study shown improvement in GSR values following electrical stimulation and the reason for this may be anatomy of conductive pathway in the lower limb from spinal cord at lower thoracic cord (T9-10) (Ogura et al, 2004). The intact sympathetic conductive pathway may remains intact in the patient.

Post-stimulation results shown mild improvement in skin temperature and were supported by Attia et al. (1983), observed increase in the muscle temperature of $2.9^{\circ} \mathrm{C}$, deep body temperature increase $36.9 \pm 0.1^{\circ} \mathrm{C}$ in response electrically induced exercise for $30 \mathrm{~min}$. The sentient skin areas are involved both in sensation and in the autonomic thermoregulatory responses. The possible underlying mechanism of increase skin temperature, below the interrupted autonomic dermatome level in SCI, were the presence of some local reflexes of vasoconstriction and dilation. The immediate increase in the skin temperature following stimulation can be due to the stimulation of A-delta and Cafferent fibers and local vasodilation over the skin. Increase in muscle and skin blood flow of foot occurred due to inhibition of alpha adrenergic vasoconstrictor fibers and stimulation of cholinergic vasodilator fibers (Rhonda et al, 1995).

On the basis of results and discussion, present study concluded that surface spinal stimulation has effect over cystometric values of urodynamics, skin resistance and skin temperature in subjects with spinal cord injury. The present study found that surface spinal stimulation with medium frequency current of beat frequency $20 \mathrm{~Hz}$ was effective to improve detrusor pressure, bladder sensations, infused fluid volume and bladder capacity of the patient with spinal cord injury. Electrical stimulation over the paravertebral region shown also improvement in skin resistance, but had no significant effect over skin temperature.

\section{References}

Abbate, A.D., Cook, A. W., and Attalah, N., 1977. The effect of electrical stimulation of the thoracic spinal cord on function of bladder in multiple sclerosis. Journal of Urology, 117: 285-288.

Amarenco, G., Sheikh, Ismael., S, Even-Schneider, A., Raibaut, P., Kerdraon, J. 2003. Urodynamic effect of acute transcutaneous posterior tibial nerve stimulation in overactive bladder. Journal of Urology, 169: 2210-2215.

Attia, M., and P. Engel., (1983) "Thermoregulatory set point in patients with spinal cord injury (Spinal man)". Paraplegia, 21: 233-248.

Brindly, G.S. 1973. Emptying the bladder by stimulation ventral roots. J. Physiol. (Paris), 237: 6-15.

Campos, R. J., Dimitrejevic, M. M., Sharkey, P. C. 1978. Clinical evaluation of the effects of spinal cord stimulation on motor performance in patients with upper motor neuron lesions". Proceedings of Sixth International Symposium on External Control of Human Extremities. Yugoslav Committee for Electronics and Automation, Belgrade: 569-574.

Hutchinson, J. 1875. Clinical lecture on temperature and circulation after crushing of cervical spinal cord. Lancet, 1: 713-715.

Illis, L. S., Sedgwick, E. M., Tallis, C.T. 1980. Spinal cord stimulation in multiple sclerosis: clinical 
results. Journal of Neurology, Neurosurgery and Psychiatry, 43: 1-14.

Maheshwari, J. 2006. "Spinal Injuries: Essential Orthopedics". $3^{\text {rd }}$ ed. Mehta Publishers, chap 22, 143-152.

Ogura, T., Kubo, T., Lee, K., Katayama, Y., Kira Y., Aramaki, S. 2004. Sympathetic skin response in patients with spinal cord injury. Journal of Orthopedic Surgery, 12(1): 35-39.

Previnaire, J.G., Solar, J.M. and Perrigot, M. 1998. Is there a place for pudendal nerve maximal electrical stimulation for the treatment of detrusor hyperreflexia in spinal cord injury patients?" Spinal Cord, 36: 100.

Richardson, R. R., McLone, D. G. 1978. Percutaneous epidural neuro-stimulation for paraplegic spasticity. Surgical Neurology, 9: 153-155.

Schmidth, R. A., Jonas, U., Oleson, K.A., Janknegt, R.A., Hassouna, M.M., Siegel, S.W., van Kerrebroeck, P.E. 1999. Sacral nerve stimulation for treatment of retractory urinary urge incontinence". Sacral Nerve Stimulation Group. J. Urol., 162: 352-357.
Rhonda, J. Scudda, Helewa., Antonie, Scudds, Roger., 1995. The effect of transcutaneous electrical nerve stimulation on skin temperature in asymptomatic subjects. Physical Therapy, 75: 621-628.

Shruti, Sharma., Narkeesh, A., Arora, Mohit. 2013. Effect of surface spinal stimulation on spasticity in SCI: a single case study". STM Journals, 2: 1-7.

Sunder, S. 2010. Rehabilitation in Spinal Cord Injury. Text book of rehabilitation. $3^{\text {rd }}$ ed. Jaypee Brother Medical Publisher. chap. 22: 402-428.

Tallis, R. C., Illis, L. S., Sedgwick, E. M., Hardwidge, C., Garfield, J. S. 1983. Spinal cord stimulation in peripheral vascular disease". J. Neurology, Neurosurgery and Psychiatry, 46: 478-484.

Wang, R., Tsai, M. 2000. Effect of thorac-lumbar electric sensory stimulation on knee extensor spasticity of person who survived cerebrovascular accident. $J$. Rehabil. Res. Dev., 37(1): 73-79.

Young-Hee, Lee. 2002. Self- controlled dorsal penile nerve stimulation to inhibit bladder hyperreflexia in incomplete spinal cord injury: A case report. Arch. Pys. Med. Rehabil., 83: 273-77. 